\title{
Unusual spontaneous and training induced visual field recovery in a patient with a gunshot lesion
}

\author{
D A Poggel, E Kasten, E M Müller-Oehring, B A Sabel, S A Brandt
}

\begin{abstract}
Over a period of more than 3 years, changes in visual and neuropsychological functions were examined in a patient with a visual field defect caused by a cerebral gunshot lesion. Initially, the patient had been completely blind, but after 6 months of spontaneous recovery, he showed a homonymous bilateral lower quadrantanopia and impairment of higher visual functions. Unexpectedly, recovery still continued after the first 6 months. This process was documented in detail by visual field examinations using high resolution perimetry. When visual field size had stabilised almost 16 months after the lesion, further improvement could be achieved by visual restitution training. The duration and extent of spontaneous recovery were unusual. In spontaneous as well as in training induced recovery, progress was mainly seen in partially defective areas (areas of residual vision) along the visual field border. Thus, it is speculated that modulation of perceptual thresholds in transition zones of visual field defects contributes to spontaneous and training induced recovery.

(F Neurol Neurosurg Psychiatry 2001;70:236-239)
\end{abstract}

Institute of Medical Psychology, Otto-von-Guericke University, Leipziger Strasse 44, 39120 Magdeburg, Germany

D A Poggel

E Kasten

E M Müller-Oehring

B A Sabel

Department of Neurology, Charité, Humboldt University, Schumannstrasse 20-21,

10117 Berlin, Germany

S A Brandt

Correspondence to: Dr B A Sabel@

medizin.uni-magdeburg.de

Received 13 March 2000 and in revised form

29 September 2000

Accepted 11 October 2000 field size could not be ruled out (for example, variability of perimetric measurements, change of detection strategies, or compensatory eccentric fixation) (see also Balliet et $a l^{\beta}$ for a review). However, more recent, methodologically well controlled studies provided evidence for training induced recovery of visual functions. ${ }^{45}$

Here, we report on a patient with a traumatically induced visual field defect showing significant spontaneous recovery and considerable further progress during visual restitution training. For the first time we could show in detail that spontaneous as well as training induced improvement take place in the area of residual vision and that both processes seem to be based on a common mechanism - that is, the modulation of perceptual thresholds in partially defective areas.

\section{Case report}

A 29 year old man with no history of neurological disease was attacked and shot in the back of his head. When regaining consciousness in the hospital, he complained of a complete loss of vision. Initially he also had anosmia, reduced vigilance, and a mild left sided hemiparesis. Reduction of vigilance and hemiparesis recovered completely within days. After 1 week, vision had recovered in the right upper quadrant, and central vision was sufficient to perform a neuropsychological examination which disclosed a slowing of reaction times as well as an impairment of short term memory and visuospatial functions. Verbal intelligence was normal.

Six months after the incident, we examined the patient for the first time in our department. General and cardiovascular examination yielded normal results. Higher cortical functions and cranial nerves were normal except for a bilateral lower quadrantanopia and hyposmia. Best corrected visual acuity was $100 \%$. Muscle tone, muscle strength, and reflexes were normal and symmetric. There was hypaesthesia in a region at the back of the head where the bullet had entered, otherwise sensation was normal. In a detailed neuropsychological examination, his performance was normal, except in visuospatial tasks and in tests involving a considerable amount of visual scanning (see below). Subjectively, the patient had difficulties in estimating direction and speed of moving objects. This caused problems 

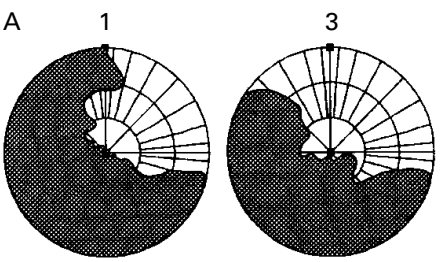

28

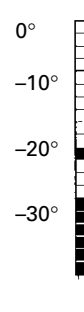

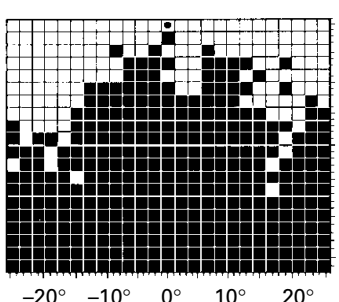

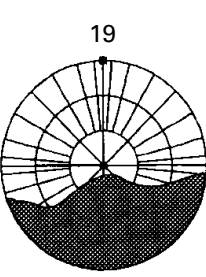

50

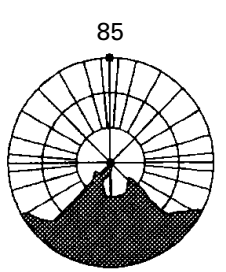

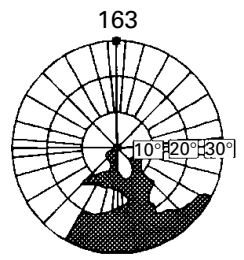

85

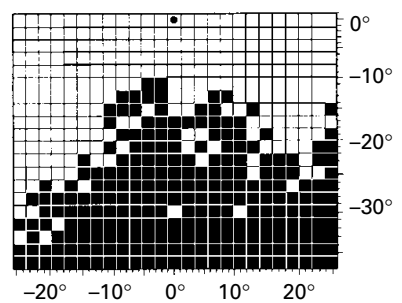

176

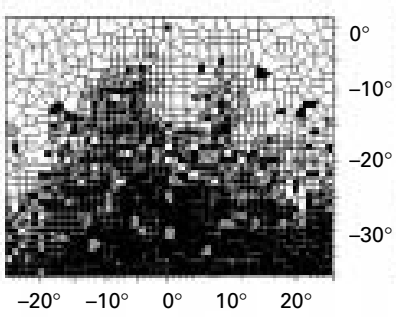

120

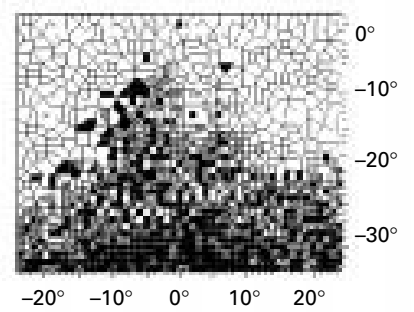

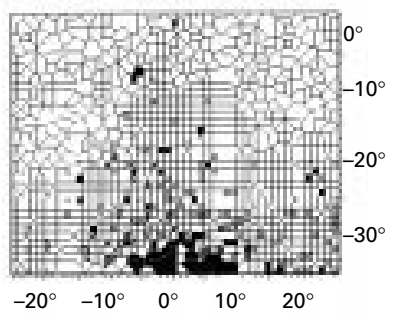

Figure 1 Spontaneous and training induced recovery of visual field. (A) Perimetric measurements (grey=blind, white $=$ intact); weeks 1, 3, 19, 85 (spontaneous recovery), and 163 (training induced recovery) after lesion. (B) Measurements of lower visual field with computer based high resolution perimetry at weeks 28, 50, and 85. (C) Results from the beginning of the 1st training unit (week 99), the end of the 3rd training unit (week 120), and the end of the 8th training-unit (week 176); five subsequent training sessions are superimposed in each picture; grey areas correspond to partially defective regions of visual field.

riding a bicycle, pouring liquids into a glass, and walking through crowds of people.

Axial CT images (2 mm slice thickness) and coronal reconstructions showed that the bullet had entered the left occipital lobe (about $5 \mathrm{~cm}$ cranial and $3 \mathrm{~cm}$ lateral to the inion) and followed a trajectory through the interhemispheric fissure into the right temporal lobe, where the bullet is still located. A hypodense area involving the upper part of the cuneus and the caudal part of the precuneus bilaterally could be identified. The lesion extended bilaterally to the ventral part of the upper calcarine bank, but spared striate cortex in the lower calcarine bank and the occipital poles. In the right hemisphere the hypodense area extended into the posterior part of the medial temporal gyrus.

\section{Methods}

Visual field recovery was found with different methods of quantitative perimetry (Allergan Humphrey $60^{\circ}$, Octopus $90^{\circ}$, Tübinger Automated Perimeter $30^{\circ}$ and $90^{\circ}$; see fig 1 ; see also Lachenmeyer and Vivell ${ }^{6}$ for description).

Additionally, we used a high resolution computer based perimetric test ${ }^{7}$ for more detailed examination of the central visual field. Testing was done in a darkened room (background luminance $=1.5 \mathrm{Lx}$ ) in front of a computer screen covering $54.8^{\circ}$ horizontally and $42.3^{\circ}$ vertically. White light stimuli (luminance $=96$ $\mathrm{cd} / \mathrm{m} 2 ;$ size $=0.76^{\circ}$; presentation time $=150 \mathrm{~ms}$, background $=26 \mathrm{~cd} / \mathrm{m}^{2}$ ) were presented in random order at 474 positions in a grid of $25 \times 19$ stimulus locations. The subject was instructed to keep his eyes on the fixation point throughout the test and to press the space bar on the computer keyboard on detection of a stimulus or of a fixation control (an isoluminant change of the fixation point's colour). Additionally, eye position was controlled by the experimenter noting the subject's fixation behaviour in a mirror. Interstimulus intervals were randomised to prevent guessing behaviour. Total duration of the visual field test was about 20 minutes. The number of hits, misses, and false positives as well as reaction times were registered by the program. Positions of correctly detected stimuli and misses were plotted as white and black squares in the stimulus grid, respectively. A variation in this perimetric procedure allowed for the testing of colour discrimination and form recognition.

For visual field enlargement, we applied computer based visual restitution training. ${ }^{4}$ Here, luminous stimuli were presented at random locations in a previously defined training area on a dark computer screen, each increasing in brightness from dark grey $\left(30 \mathrm{~cd} / \mathrm{m}^{2}\right)$ to bright white $\left(96 \mathrm{~cd} / \mathrm{m}^{2}\right)$ over a period of 2000 ms. Stimulus size, fixation control, mode of response, and viewing distance were the same as in the visual field test. Training was performed at home for 1 hour daily. Treatment 


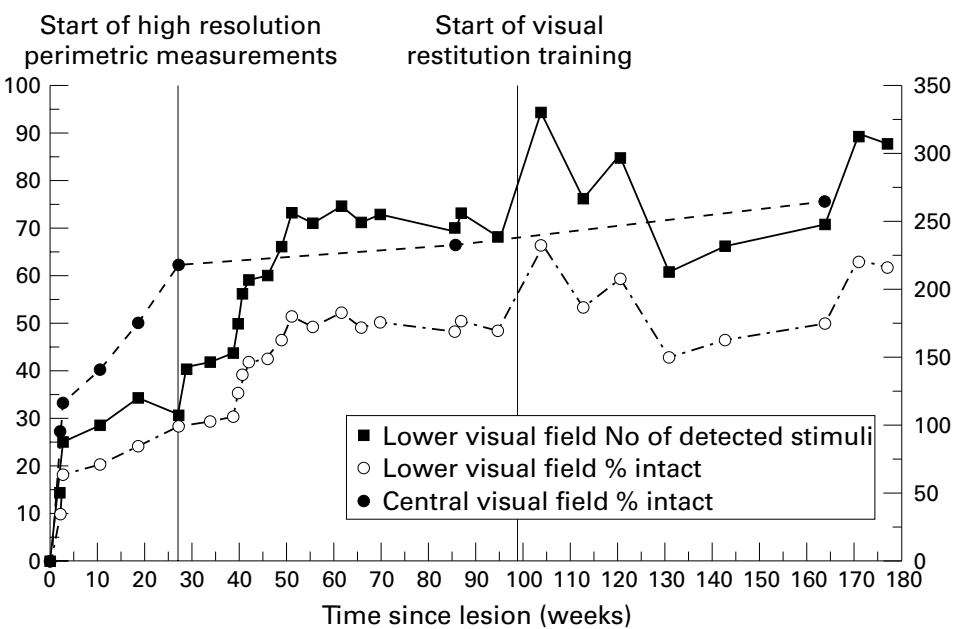

Figure 2 Course of spontaneous and training induced recovery. Graphs show the enlargement of visual field over the complete course of spontaneous and training induced recovery. The dotted line with the open circles depicts the increase of per cent intact lower visual field as measured by high resolution perimetry (fixation point at upper edge of the screen). The dashed line with the filled circles shows changes of per cent intact area of the central visual field measured with standard perimetry. The solid line demonstrates the parallel increase of the number of detected stimuli in high resolution perimetry of the lower visual field. parallel, colour perception and form recognition recovered in the transition zone, and he subjectively perceived an improvement of visual orientation and spatial perception.

After visual field size had remained constant for more than 7 months (week 51 to 94 ), visual restitution training was started.

The patient showed a remarkable but variable further increase of visual field size over the next 80 weeks of training (fig 1). Again, this improvement was found almost exclusively in the transition zones of the scotoma with peripheral parts of the visual field defect recovering more and faster than central parts. Interestingly, we found a striking discrepancy between the position of the visual field border in our standard perimetric measurements versus the training related perimetric results. Obviously, our patient was able to detect light stimuli during the training program when they were presented for $2000 \mathrm{~ms}$, but he could not perceive a light stimulus at the same position when it appeared only for $150 \mathrm{~ms}$ in the perimetric test.

We quantified recovery over time using two measures (fig 2): (1) increase of per cent intact lower visual field and (2) number of detected stimuli. Mean size of the lower intact visual field in the period of spontaneous recovery (week 1 to 51 ) was $27.8 \%$ (SD12.9\%) - that is, 137 of 499 stimuli (SD 65.2) detected in high resolution perimetry. During that time, visual field size increased substantially from $0 \%$ to $51 \%$ intact. Between weeks 51 and 94 visual field testing yielded stable results (baseline) with an average intact lower field of $49.6 \%$ (SD1.41\%) - that is, 250/499 detected stimuli (SD7.4). In the period of visual field training (weeks 94 to 176), mean visual field size increased again with occasional peak levels reaching $66 \%$ intact visual field size (330/499 stimuli). Albeit, mean size of intact visual field during training was $54.8 \%$ (SD $8.6 \%$ ) - that is, 273/499 stimuli (SD42.6), which was not significantly different from baseline (weeks 51 to 94). However, during the last two measurements of the training period his visual field size had clearly improved in comparison with the baseline level. He detected luminous stimuli, in particular regions of the transition zone where he had never perceived them before.

Subjectively, the patient reported an improvement in everyday function - for example, less difficulties riding a bicycle, shaking somebody's hand, or avoiding obstacles on the ground. However, visual exploration and the perception of movements were still difficult for him, although neither a test of visual scanning nor tests of higher order visual functions (object agnosia, prosopagnosia, depth perception) showed any impairment.

Twenty eight weeks after lesion, baseline testing with computer based perimetry ${ }^{7}$ was begun. Unexpectedly, visual field size still increased over the next months so that restitution training was not started. During that period, we found a gain of more than $20 \%$ in perimetric tests of the lower visual field until measurements stabilised 16 months after the gunshot. This improvement was found almost exclusively in partially defective areas (transition zones) at the visual field border (fig 1). In

\section{Discussion}

The bilateral lower quadrantanopia was a result of traumatic injury of both occipital lobes and is in full agreement with earlier descriptions of visual field defects. Our research interest was focused on the time course and phenomenology of spontaneous recovery 
from visual field defects and additional effects of systematic visual field training.

Three findings are unusual in the case reported here. In most studies on spontaneous recovery, the maximum duration of visual field increase ranged between 3 weeks and 6 months. ${ }^{11}$ By contrast, the patient's spontaneous recovery ended only 16 months after lesion. Secondly, the amount of spontaneous improvement was striking in that he regained almost two thirds of his visual field although average recovery in patients with complete cortical blindness usually amounts to about $28 \% .{ }^{11}$ Thirdly, even after the termination of spontaneous recovery and a long period of stable visual field size, further-albeit smaller and inconstant-improvement could be achieved by systematic stimulation during visual field training starting almost 2 years after the lesion.

In concordance with earlier studies, ${ }^{4}{ }^{12} \mathrm{im}$ provement was mainly found at the borders of visual field defects - that is, in partially defective areas. ${ }^{13}$ Analysis of reaction times to light stimuli in the perimetric test showed a considerable slowing of responses to stimuli presented in the transition zone compared with those appearing in completely intact areas. Subjectively, stimuli seem to be reduced in brightness and do not have clear contours. Additionally, light stimuli cannot be perceived when presentation time is too short, explaining the difference between the visual field border found in our standard perimetric tests and training related perimetric measurements. These findings suggest that perceptual thresholds are increased in areas of residual vision. During the process of spontaneous as well as training induced recovery, these thresholds are reduced so that perception is gradually normalised. This mechanism has been postulated by Zihl and von Cramon ${ }^{1}$ as the basis of their training results, but it has not been related before to detailed observations of spontaneous and training induced increase of visual field size like in the case presented here. Therefore, we conclude that partially defective neuronal areas representing transition zones in the visual field may be crucial not only for spontaneous improvement but brain plasticity and functional recovery in these areas can also be induced by systematic stimulation as provided during visual restitution training.

This work was supported by grants from the state of Saxonia-Anhalt (FKZ: 1367A/0083B, 820A/8283B) and the Otto-von-Guericke University, Magdeburg, by grants from the Deutsche Forschungsgemeinschaft (Sa 433/ 6-1,2) and a scholarship from the "Graduiertenkolleg Biologische Grundlagen von Erkrankungen des Nervensystems". We thank Ulrike Bunzenthal for help with data acquisition and Christoph Ploner for helpful comments on the manuscript.

1 Zihl J, von Cramon DY. Visual field recovery from scotoma in patients with postgeniculate damage. A review of 55 cases. Brain 1985;108:335-65.

2 Balliet R, Blood KMT, Bach-y-Rita P. Visual field rehabilitation in the cortically blind? F Neurol Neurosurg Psychiatry 1985;48:1113-24.

3 Pambakian ALM, Kennard C. Can visual function be restored in patients with homonymous hemianopia? $B r f$ restored in patients with hon
Ophthalmol 1997;81:324-8.

4 Kasten E, Wüst S, Behrens-Baumann W, et al. Computerbased training for the treatment of partial blindness. Nat Med 1998;4:1083-7.

5 Kasten E, Poggel DA, Müller-Oehring EM, et al. Restoration of vision II: residual functions and training-induced visual field enlargement in brain-damaged patients. Restorative Neurology and Neuroscience 1999;15:273-87.

6 Lachenmayr BJ, Vivell PMO. Perimetrie. Stuttgart: Thieme Verlag, 1992.

7 High resolution perimetry (HRP)/ visual restitution training (VRT). Nova vision: software for diagnosis of visual field defects. Magdeburg, Germany: 1998. Nova Vision AG (www.nova-vision.org)

8 Kasten E, Strasburger H, Sabel BA. Programs for diagnosis Kasten E, Strasburger H, Sabel BA. Programs for diagnosis and therapy of visual field

9 Brickenkamp R, ed. Handbuch psychologischer und pädagogischer Tests. Göttingen: Hogrefe Verlag, 1997.

10 Gruesser OJ, Landis T. Vision and visual dysfunction: visual agnosias and other disturbances of visual perception and cognition. Vol 12. Houndmills: Macmillan, 1991.

11 Tiel-Wilck, K. Rückbildung homonymer Gesichtsfelddefekte nach Infarkten im Versorgungsgebiet der Arteria cerebri posterior [Dissertation]. Berlin, Germany: Freie Universität, 1991.

12 Zihl J, von Cramon DY. Restitution of visual function in patients with cerebral blindness. I Neurol Neurosurg Psychiatry 1979;42:312-22.

13 Sabel BA. Unrecognized potential of surviving neurons: within-systems plasticity, recovery of function, and the hypothesis of minimal residual structure. The Neuroscientist 1997;3:366-70 